\title{
The Effect of Two Calcium Silicate Materials on the Fracture Strength of Simulated Immature Teeth during Regenerative Endodontic Treatment
}

\author{
Hadeel Y. Edrees ${ }^{1}$, Amna Y. Siddiqui ${ }^{2}$, Murtadha M. Almousa ${ }^{3}$, Reem A. Ajaj ${ }^{4}$, Ehab N. Alshouibi ${ }^{5}$, Osama S. Alothmani $^{6}$ \\ 1, 2, 3, 6 Department of Endodontics, King Abdulaziz University, Jeddah, Saudi Arabia, ${ }^{4}$ Department of \\ Restorative Dentistry, King Abdulaziz University, Jeddah, Saudi Arabia, ${ }^{5}$ Department of Dental Public \\ Health, King Abdulaziz University, Jeddah, Saudi Arabia.
}

\section{ABSTRACT}

\section{BACKGROUND}

Necrotic immature permanent teeth undergoing Regenerative Endodontic Treatment (RET) are subjected to functional forces that might lead to their fracture before achieving apical closure. This study compared the fracture strength of simulated immature teeth treated with RET that were subjected to cyclic loading.

\section{METHODS}

Thirty human anterior teeth were randomly assigned into three groups (Group I: control, groups II and III: prepared to simulate immature teeth then subjected to RET with EndoSequence Root Repair Material (ESRRM) and white Mineral Trioxide Aggregate (WMTA) used as coronal barriers, respectively). All specimens were mounted on customized mold and subjected to cyclic loading until fracture or to a maximum of 165,000 cycles. The number of endured cycles and the maximum load applied at failure were recorded. Chi-square analysis was done to compare the frequency of fracture while One - Way ANOVA followed by Tukey's Post Hoc test were done to compare means for the number of endured cycles and the maximum load applied to failure.

\section{RESULTS}

There was no significant difference between the three groups regarding the frequency of fracture $(\mathrm{P}>0.05)$. There was no significant difference between the mean number of cycles endured or force at failure between group I and II or groups II and III $(\mathrm{P}>0.05)$. However, group III endured significantly less force $(\mathrm{P}=0.008)$ and significantly lower number of cycles $(\mathrm{P}=0.014)$ compared to group I.

\section{CONCLUSIONS}

Within the limitation of this study, there was no significant difference between ESRRM and WMTA regarding their reinforcement of teeth treated with RET.

\section{KEY WORDS}

EndoSequence Root Repair Material, Fracture Strength, Immature Teeth, Mineral Trioxide Aggregate, Regeneration
Corresponding Author: Dr. Hadeel Y. Edrees, Department of Endodontics, Faculty of Dentistry King Abdulaziz University, Abdullah Sulayman St, Jeddah - 21589, Saudi Arabia.

E-mail: hedrees@kau.edu.sa

DOI: $10.14260 / j e m d s / 2021 / 552$

How to Cite This Article:

Edrees HY, Siddiqui AY, Almousa MM, et al. The effect of two calcium silicate materials on the fracture strength of simulated immature teeth during regenerative endodontic treatment. J Evolution Med Dent Sci 2021;10(33):2702-2706, DOI: $10.14260 / \mathrm{jemds} / 2021 / 552$

Submission 30-01-2021,

Peer Review 10-07-2021,

Acceptance 18-07-2021,

Published 16-08-2021.

Copyright (C) 2021 Hadeel Y. Edrees et al. This is an open access article distributed under Creative Commons Attribution License [Attribution 4.0 International (CC BY 4.0)] 


\section{BACKGROUND}

Trauma, caries, and developmental malformations are the usual causes for pulp necrosis in immature permanent teeth consequently leading to their arrested root development.1-4 Immature teeth are characterized by thin dentinal walls, large pulp chambers and open apices 5 that make them prone to fracture specially at the cervical area. ${ }^{6}$ Endodontic treatment becomes challenging due to lack of apical seat necessary for prevention of extrusion of root filling. ${ }^{3}$ Apexification or regenerative endodontic treatment (RET) are advised for such condition. ${ }^{7}$

Apexification utilizing mineral trioxide aggregate (MTA) is a successful choice of intervention to manage necrotic immature teeth. However, it leads to limited gain in root length and / or width. ${ }^{3,8-12}$ RET has been advocated to regenerate a functional dentin - pulp complex. ${ }^{13}$ It is a recent tissue engineering modality that allows continued root development resulting in increased gain in radicular length and width ${ }^{3}$ and reducing the risk of tooth fracture.

Recommended capping materials used for RET are the calcium silicate cements such as MTA, endosequence root repair material (ESRRM) and TotalFill.7 MTA is used in regenerative studies as a coronal barrier to promote revascularization. ${ }^{14}$ However, it has the disadvantage of poor handling properties, long setting time and possibility of discoloration. ${ }^{15}$ ESRRM is a recently introduced calcium silicate composed of calcium silicate, calcium phosphate monobasic, calcium hydroxide and zirconium oxide. It is available either in a premixed injectable paste or fast set putty consistency. ${ }^{16}$ It is biocompatible, ${ }^{17,18}$ has limited discoloration potential compared to white MTA, ${ }^{19}$ has a good sealing ability as root-end filling material 20 and has increased force to fracture in endodontically treated mature premolars. ${ }^{21}$ To the best of our knowledge, the effect of ESRRM on strengthening immature teeth subjected to RET has not been evaluated yet.

Our literature search revealed that only two studies have evaluated the in-vitro ability of MTA to strengthen teeth subjected to RET.22,23 Both studies found that the fracture strength of the MTA group was subjected to static load until fracture was significantly lower than intact mature teeth. However, static load application was done until fracture does not reflect clinical conditions. ${ }^{22}$ Further, cervical root fracture was significantly more prevalent in immature teeth compared to fully formed ones. ${ }^{6}$ It has been suggested that such high prevalence is probably due to fatigue cracking that extends over time leading to tooth fracture, instead of being consequent to a second traumatic impact. ${ }^{24}$ Thus, there is a need to evaluate the ability of MTA to strengthen teeth undergoing RET when subjected to cyclic loading.

Continued root development after RET requires time, during which these vulnerable teeth are subjected to functional forces and might be subjected to additional catastrophic traumatic impact leading to their fracture. Hence, until sufficient dentin deposition to strengthen such teeth is achieved, the use of coronal barrier that could enhance the fracture strength of immature teeth is warranted. The objective of this study was to compare the difference in the fracture strength of simulated immature teeth subjected to cyclic loading when WMTA or ESRRM were used as coronal barriers during RET.

\section{METHODS}

Ethical approval was obtained from the Research Ethics Committee at the Faculty of Dentistry, King Abdulaziz University (Proposal number: 079 - 16). Study was conducted from October 2019 to January 2020. Thirty human anterior teeth extracted for periodontal disease were examined under an operating microscope at 8X (Carl - Zeiss Meditec AG, Jena, Germany) to exclude carious lesions and cracks. Sample standardization was done by measuring the lingual ( F - L) and mesio-distal (M - D) dimensions using a digital caliper (Mitutoyo, Tokyo, Japan) at the cemento-enamel junction (CEJ). Selected teeth had mean dimension of $7.17 \pm 0.5 \mathrm{~mm}$ for $\mathrm{F}$ - L and $5.80 \pm 0.5 \mathrm{~mm}$ for $\mathrm{M}$ - D measurement. All selected teeth were within $20 \%$ range from the mean value. Using low -speed diamond saw, root ends were reduced to standardizing root lengths at $12 \pm 1 \mathrm{~mm}$ as measured from the apical end to the CEJ. ${ }^{25}$ Teeth were randomly assigned into three groups $(\mathrm{N}$ $=10 /$ group). Teeth in Group I (control) were intact mature teeth. Teeth in Groups II and III were prepared to simulate immature teeth then subjected to RET with ESRRM (Brasseler, Savannah, GA, USA) and ProRoot WMTA (Dentsply Tulsa Dental, Tulsa, OK, USA) used as coronal barriers, respectively.

Access was prepared in teeth of Groups II and III using high speed round bur size 4 and Endo Z bur (Dentsply Maillefer, Ballaigues, Switzerland) followed by instrumentation with size $60 \mathrm{~K}$ - file at full working length. Following Jamshidi et al. ${ }^{23}$ simulation of immature teeth was done by sequential canal enlargement with Peso reamer (Dentsply Maillefer) until size \#6 (tip diameter $=1.7 \mathrm{~mm}$ ) inserted from the apical end up to $2 \mathrm{~mm}$ beyond the CEJ (Fig 1). To approximate Cvek's stage 3 root development, $3 \mathrm{~mm}$ diameter twisted drill was used to extend the preparation of the canal apical to CEJ level. 22,26 Canals were irrigated with $5 \%$ sodium hypochlorite $(\mathrm{NaOCl})$. Following AAE guidelines, ${ }^{7}$ calcium hydroxide $\left(\mathrm{Ca}(\mathrm{OH})_{2}\right)$ (Ultradent, South Jordan, UT, USA) was placed in the canals using lentulospiral and accesses were sealed with a cotton pellet and Cavit (3M ESPE, St. Paul, MN, USA) to simulate the disinfection procedure. All samples were stored at $37^{\circ} \mathrm{C}$ and $100 \%$ humidity for four weeks. Then, teeth were re-accessed and $\mathrm{Ca}(\mathrm{OH})_{2}$ was removed using $17 \%$ ethylenediaminetetraacetic acid EDTA (Ultradent, South Jordan) followed by $5 \% \mathrm{NaOCl}$ irrigation. ESRRM and WMTA mixed according to the manufacturer's recommendations were placed using MAP system (Dentsply Maillefer) $3 \mathrm{~mm}$ below the CEJ and condensed with hand pluggers. To insure adequate placement, saline moistened Gelatamp (Roeko Coltene / Whaledent, Langenau, Germany) was used as a matrix. Apical end was sealed with IRM (Dentsply, Konstanz, Germany). Periapical radiographs were taken to evaluate the adequacy of the coronal barrier placement (Figure 1). Afterwards, all samples were stored at $37^{\circ} \mathrm{C}$ and $100 \%$ humidity for 72 hours. Access was sealed with Fuji II (GC, Tokyo, Japan) and composite (Filtek P60, 3M ESPE, MN, USA). All samples preparation was done by one endodontist.

All specimens were mounted on a customized mold and subjected to cyclic loading. To mimic the periodontal membrane, root surfaces were coated with a $0.2-0.3 \mathrm{~mm}$ thick layer of polyvinyl siloxane impression material (Coltene Whaledent AG, Altstatten, Switzerland), before embedding the roots into acrylic resin. Samples were then embedded in plastic rings with the long axis of the crown at an angulation of 
45 degrees to the loading platen of the servo hydraulic testing machine ElectroPuls E3000 (Instron, Grove City, USA). Cyclic load was applied starting at a frequency of $5 \mathrm{~Hz}$ with $50 \mathrm{~N}$ force for 5000 cycles (Preconditioning phase). This was followed by stages of $100,150,200,250,300,400,500$ and $600 \mathrm{~N}$ at a maximum of 20000 cycles each. Samples were loaded until fracture or to a maximum of 165,000 cycles. ${ }^{27}$ The number of cycles endured (NCE) and the maximum load applied at failure were recorded.

\section{Statistical Analysis}

Chi-square analysis was done to compare the frequency of fracture among the three groups while One-Way ANOVA followed by Tukey's Post Hoc test were done to compare the means of NCE and the maximum load applied to failure with level of significance set at $\mathrm{P}<0.05$. Statistical analyses were done using SPSS Version 22 (Chicago, Illinois, USA).

\section{RESULTS}

Table 1 presents the frequency of fractured and intact teeth across the three groups. Chi-square test showed no significant difference in the frequency of fracture among each group or between them $(\mathrm{P}=0.816)$. One-way ANOVA showed a significant difference between the three groups regarding mean NCE until fracture $(\mathrm{P}<0.0001)$. Tukey's Post Hoc test comparing respective means [Table 2] showed no significant difference in the mean NCE of the control group when compared to the ESRRM group $(\mathrm{P}=0.654)$ or between the means of NCE of ESRRM and WMTA groups (P = 0.094). However, mean NCE for the WMTA group was significantly less than that for the control group $(\mathrm{P}=0.014)$. Obviously, all teeth that remained intact at the end of cyclic loading sustained 165000 cycles.

Another One-Way ANOVA showed a significant difference between the three groups regarding mean force endured until fracture $(\mathrm{P}<0.0001)$. Tukey's Post Hoc test comparing the mean forces endured by each group [Table 2] showed that there was no significant difference in the mean force at fracture endured by the control group when compared to ESRRM group $(\mathrm{P}=0.539)$. The same applied to the comparison of the means for force endured at fracture for ESRRM and WMTA $(\mathrm{P}=0.082)$. However, mean force endured at fracture for the WMTA group was significantly less than that for the control group $(\mathrm{P}=0.008)$. All teeth that remained intact at the end sustained $600 \mathrm{~N}$.

\begin{tabular}{|cccc|}
\hline Group & $\begin{array}{c}\text { Frequency of Fractured } \\
\text { Teeth }\end{array}$ & $\begin{array}{c}\text { Frequency of Intact } \\
\text { Teeth }\end{array}$ & Total \\
Control & $6(60 \%)$ & $4(40 \%)$ & 10 \\
ESRRM & $7(70 \%)$ & $3(30 \%)$ & 10 \\
WMTA & $7(70 \%)$ & $3(30 \%)$ & 10 \\
Total & $20(66.7 \%)$ & $10(33.3 \%)$ & 30 \\
\hline \multicolumn{4}{r}{ Table 1. Frequency of Fractured and } \\
& Intact Teeth across the Three Groups & \\
\hline
\end{tabular}

\begin{tabular}{|ccc|}
\hline Group & $\begin{array}{c}\text { No. of NCE at Fracture } \\
\text { (Mean } \pm \text { SD) }\end{array}$ & $\begin{array}{c}\text { Force (N) Endured at } \\
\text { Fracture } \\
\text { (Mean } \pm \text { SD) }\end{array}$ \\
Control & $116982.17 \pm 25353$ & $433.33 \pm 121$ \\
ESRRM & $106454.29 \pm 26192$ & $385.71 \pm 118$ \\
WMTA & $63522 \pm 50574$ & $235.71 \pm 131$ \\
\hline \multicolumn{2}{|c|}{ Table 2. Mean \pm SD for the Number of Cycles Endured (NCE) } \\
& and Force at Fracture for Each Group \\
\hline
\end{tabular}

\section{DISCUSSION}

This study compared the fracture strength of teeth undergoing RET using ESRRM or WMTA as coronal barriers when subjected to cyclic loading. Despite the lack of significance on the frequency of fracture across the three groups, the results showed that ESRRM might be a better option for RET compared to WMTA, since there was no significant difference between the NCE or forces sustained at fracture between ESRRM group and the control group. However, teeth fractured in the WMTA group at significantly lower NCE and force compared to control group.

Extensive efforts to simulate clinical condition were attempted while designing our methodology. Teeth were embedded in acrylic resin lined with polyvinyl siloxane impression material to simulate periodontal membrane. ${ }^{28}$ Immature teeth simulation was done to mimic Cvek's stage 3 root development in which the root canal ratio in the $\mathrm{M}-\mathrm{D}$ dimension at the CEJ is approximately $1: 1 .{ }^{26}$ In addition, teeth were embedded to allow a loading angle of 45 degrees that represents class I occlusion between maxillary and mandibular incisors. ${ }^{24}$ We opted to subject the teeth to cyclic 27 instead of static ${ }^{22}$ loading to simulate masticatory forces in the oral cavity while eating. Adopting combination of cyclic, thermal and / or static loading protocols might lead to better simulation of clinical conditions. Studies assessing fatigue resistance should consider the upper range of possible forces rather than the average loads and contact angles encountered in vivo. ${ }^{29}$ The magnitude of load generated by masticatory activity and the contact angle of load fluctuates between individuals and may also differ during the day. ${ }^{30}$ Thus, the simulated cyclic loading we applied might not be an exact replica of the clinical condition.

Our results showed that RET with WMTA led to fracture at significantly lower NCE and force compared to the control group indicating reduced fracture strength of these teeth. This concurs with previous findings. ${ }^{22,23}$ It must be pointed out that the former study ${ }^{22}$ filled the entire length of the canals with MTA which does not resemble RET. Further, they immersed teeth in phosphate - buffered solution for 12 months before subjecting them to fracture. Such approach should lead to hydroxyapatite formation at MTA - dentin interface. ${ }^{31}$ Nevertheless, the reported fracture resistance for the MTA was significantly lower than intact mature teeth. ${ }^{22}$ The reduced strengthening ability of MTA could be attributed to its inadequate bonding to dentin and its reduced resistance to tensile forces.32,33 Further, functional loading impacts the sealing of root filling material. ${ }^{34} \mathrm{Wu}$ et al. ${ }^{35}$ demonstrated that when the entire root canal is filled with MTA, cyclic loading causes MTA disintegration.

We found that NCE and force at fracture for the ESRRM group were comparable to intact mature teeth $(\mathrm{P}>0.05)$. We couldn't compare these findings with other studies since the current investigation is the first to assess the strengthening effect of ESRRM on immature teeth subjected to RET. More studies are needed to further evaluate ESRRM's possible enforcing action during REP.

Jamshidi et al. ${ }^{23}$ compared the in-vitro fracture resistance of simulated immature teeth when they were treated by MTA apexification, teeth undergoing REP and those that finished REP. There was no significant difference between the three groups regarding their fracture strength indicating that these 
approaches did not lead to appreciable radicular fortification. They concluded that the increased thickness of the middle and apical regions of the roots achieved at the end of REP had no significant effect on cervical fracture strength. It must be pointed out that the end result of REP cannot be currently simulated because it is a consequence of in-vivo process. Hence, the reinforcement achieved at the end of RET can only be evaluated through long-term clinical trials.

\section{CONCLUSIONS}

In conclusion, within the limitation of this study, there was no significant difference between ESRRM and WMTA regarding their reinforcement of teeth treated with RET. Further studies with more standardized larger samples are needed to assess the fracture strength of teeth undergoing RET.

\section{Limitations}

One of the limitations of this study is the sample size which might have underestimated the reported results. In light of the central limited theorem, which states that the sample size of at least 30 subjects is sufficient for achieving statistical significance provided that the sample is normally distributed, out of 36 we opted to include 30 teeth in our investigation. The simulated cyclic loading applied ${ }^{27}$ failed to consistently fracture teeth and neither material consistently improved their fracture strength. Regardless of our attempt to standardize the investigated sample, difference in the nature, composition and source of teeth might have contributed to the variability in the reported findings.

Data sharing statement provided by the authors is available with the full text of this article at jemds.com.

Financial or other competing interests: None.

Disclosure forms provided by the authors are available with the full text of this article at jemds.com.

\section{REFERENCES}

[1] Cehreli ZC, Isbitiren B, Sara S, et al. Regenerative endodontic treatment (revascularization) of immature necrotic molars medicated with calcium hydroxide: a case series. J Endod 2011;37(9):1327-30.

[2] Cehreli ZC, Sara S, Aksoy B. Revascularization of immature permanent incisors after severe extrusive luxation injury. J Can Dent Assoc 2012;78:C4.

[3] Lin J, Zeng Q, Wei X, et al. Regenerative endodontics versus apexification in immature permanent teeth with apical periodontitis: a prospective randomized controlled study. J Endod 2017;43(11):1821-27.

[4] Wang Y, Zhu X, Zhang C. Pulp revascularization on permanent teeth with open apices in a middle-aged patient. J Endod 2015;41(9):1571-75.

[5] Singh RK, Shakya VK, Khanna R, et al. Interventions for managing immature permanent teeth with necrotic pulps. Cochrane Database Syst Rev 2017;2017(6):CD012709.

[6] Cvek M. Prognosis of luxated non-vital maxillary incisors treated with calcium hydroxide and filled with gutta- percha. A retrospective clinical study. Endod Dent Traumatol 1992;8(2):45-55.

[7] Chrepa V. Regenerative endodontic therapy: a treatment with substantial benefits. American Association of Endodontics Communiqué 2016.

[8] El-Meligy OA, Avery DR. Comparison of apexification with mineral trioxide aggregate and calcium hydroxide. Pediatr Dent 2006;28(3):248-53.

[9] Jeeruphan T, Jantarat J, Yanpiset K, et al. Mahidol study 1: comparison of radiographic and survival outcomes of immature teeth treated with either regenerative endodontic or apexification methods: a retrospective study. J Endod 2012;38(10):1330-36.

[10] Mente J, Leo M, Panagidis D, et al. Treatment outcome of mineral trioxide aggregate in open apex teeth. J Endod 2013;39(1):20-6.

[11] Silujjai J, Linsuwanont P. Treatment outcomes of apexification or revascularization in nonvital immature permanent teeth: a retrospective study. J Endod 2017;43(2):238-45.

[12] Witherspoon DE, Small JC, Regan JD, et al. Retrospective analysis of open apex teeth obturated with mineral trioxide aggregate. J Endod 2008;34(10):1171-6.

[13] Hargreaves KM, Diogenes A, Teixeira FB. Treatment options: biological basis of regenerative endodontic procedures. J Endod 2013;39(3 Suppl):S30-43.

[14] Law AS. Considerations for regeneration procedures. J Endod 2013;39(3 Suppl):S44-56.

[15] Torabinejad M, Hong C, McDonald F, et al. Physical and chemical properties of a new root-end filling material. J Endod 1995;21(7):349-53.

[16] Wang Z. Bioceramic materials in endodontics. Endod Topics 2015;32(1):3-30.

[17] Damas BA, Wheater MA, Bringas JS, et al. Cytotoxicity comparison of mineral trioxide aggregates and endosequence bioceramic root repair materials. J Endod 2011;37(3):372-5.

[18] Willershausen I, Wolf T, Kasaj A, et al. Influence of a bioceramic root end material and mineral trioxide aggregates on fibroblasts and osteoblasts. Arch Oral Biol 2013;58(9):1232-7.

[19] Możyńska J, Metlerski M, Lipski M, et al. Tooth discoloration induced by different calcium silicate-based cements: a systematic review of in vitro studies. J Endod 2017;43(10):1593-601.

[20] Chen I, Karabucak B, Wang C, et al. Healing after root-end microsurgery by using mineral trioxide aggregate and a new calcium silicate-based bioceramic material as rootend filling materials in dogs. J Endod 2015;41(3):389-99.

[21] Topçuoğlu HS, Tuncay Ö, Karataş E, et al. In vitro fracture resistance of roots obturated with epoxy resin-based, mineral trioxide aggregate-based and bioceramic root canal sealers. J Endod 2013;39(12):1630-33.

[22] Elnaghy AM, Elsaka SE. Fracture resistance of simulated immature teeth filled with biodentine and white mineral trioxide aggregate-an in vitro study. Dent Traumatol 2016;32(2):116-20.

[23] Jamshidi D, Homayouni H, Majd NM, et al. Impact and fracture strength of simulated immature teeth treated with mineral trioxide aggregate apical plug and fiber post versus revascularization. J Endod 2018;44(12):1878-82.

[24] Seghi RR, Nasrin S, Draney J, et al. Root fortification. J Endod 2013;39(3 Suppl):S57-62. 
[25] Hemalatha H, Sandeep M, Kulkarni S, et al. Evaluation of fracture resistance in simulated immature teeth using resilon and ribbond as root reinforcements--an in vitro study. Dent Traumatol 2009;25(4):433-8.

[26] Çiçek E, Yılmaz N, Koçak MM, et al. Effect of mineral trioxide aggregate apical plug thickness on fracture resistance of immature teeth. J Endod 2017;43(10):1697700.

[27] Foong JK, Judge RB, Palamara JE, et al. Fracture resistance of titanium and zirconia abutments: an in vitro study. J Prosthet Dent 2013;109(5):304-12.

[28] Bortoluzzi E, Souza E, Reis JMdSN, et al. Fracture strength of bovine incisors after intra-radicular treatment with mta in an experimental immature tooth model. Int Endod J 2007;40(9):684-91.

[29] FDA. Class ii special controls guidance document: rootform endosseous dental implants and endosseous dental implant abutments. Washington, D.C.: U.S. Department of Health and Human Services 2004.

[30] Nishigawa K, Bando E, Nakano M. Quantitative study of bite force during sleep associated bruxism. J Oral Rehabil 2001;28(5):485-91.
[31] Sarkar N, Caicedo R, Ritwik P, et al. Physicochemical basis of the biologic properties of mineral trioxide aggregate. J Endod 2005;31(2):97-100.

[32] Nagas E, Uyanik O, Altundasar E, et al. Effect of different intraorifice barriers on the fracture resistance of roots obturated with resilon or gutta-percha. J Endod 2010;36(6):1061-3.

[33] Tay FR, Pashley DH. Monoblocks in root canals: a hypothetical or a tangible goal. J Endod 2007;33(4):3918.

[34] Bishop D, Griggs J, He J. Effect of dynamic loading on the integrity of the interface between root canal and obturation materials. J Endod 2008;34(4):470-73.

[35] Wu M, Palamara J, Parashos P. Behavior of mineral trioxide aggregate apical plugs and root fillings under cyclic loading. J Investig Clin Dent 2017;8(3):e12226.

[36] Kwak SG, Kim JH. Central limit theorem: the cornerstone of modern statistics. Korean J Anesthesiol 2017;70(2):144-56. 